\title{
Asthma and treatment with inhaled corticosteroids: associations with hospitalisations with pneumonia
}

\author{
Emil Ekbom ${ }^{1}$ Jennifer Quint ${ }^{2}$, Linus Schöler ${ }^{3}$, Andrei Malinovschi ${ }^{4}$, Karl Franklin $^{5}$, Mathias Holm ${ }^{3}$, Kjell Torén ${ }^{3}$, \\ Eva Lindberg ${ }^{1}$, Deborah Jarvis ${ }^{2}$ and Christer Janson ${ }^{1,2^{*}}$ (D)
}

\begin{abstract}
Background: Pneumonia is an important cause of morbidity and mortality. COPD patients using inhaled corticosteroids (ICS) have an increased risk of pneumonia, but less is known about whether ICS treatment in asthma also increases the risk of pneumonia. The aim of this analysis was to examine risk factors for hospitalisations with pneumonia in a general population sample with special emphasis on asthma and the use of ICS in asthmatics.

Methods: In 1999 to 2000, 7340 subjects aged 28 to 54 years from three Swedish centres completed a brief health questionnaire. This was linked to information on hospitalisations with pneumonia from 2000 to 2010 and treatment with ICS from 2005 to 2010 held within the Swedish National Patient Register and the Swedish Prescribed Drug Register.

Results: Participants with asthma $(n=587)$ were more likely to be hospitalised with pneumonia than participants without asthma (Hazard Ratio (HR 3.35 (1.97-5.02)). Other risk factors for pneumonia were smoking (HR 1.93 (1.223.06)), $\mathrm{BMl}<20 \mathrm{~kg} / \mathrm{m} 2$ (HR $2.74(1.41-5.36))$ or BMl $>30 \mathrm{~kg} / \mathrm{m} 2$ (HR 2.54 (1.39-4.67)). Asthmatics $(n=586)$ taking continuous treatment with fluticasone propionate were at an increased risk of being hospitalized with pneumonia (incidence risk ratio (IRR) 7.92 (2.32-27.0) compared to asthmatics that had not used fluticasone propionate, whereas no significant association was found with the use of budesonide (IRR $1.23(0.36-4.20)$ ).

Conclusion: Having asthma is associated with a three times higher risk of being hospitalised for pneumonia. This analysis also indicates that there are intraclass differences between ICS compounds with respect to pneumonia risk, with an increased risk of pneumonia related to fluticasone propionate.
\end{abstract}

\section{Background}

Pneumonia is an important cause of morbidity and mortality. In a recent study from the United States the annual incidence was 24.8 patients hospitalized with community acquired pneumonia per 10,000 adults [1], whereas in Iceland, the incidence of community acquired pneumonia requiring hospitalisations was 20.6 cases per 10,000 adults/year [2]. Pneumonia is a common complication in patients with COPD. In a study of COPD patients from Swedish primary care over $40 \%$

\footnotetext{
* Correspondence: christer.janson@medsci.uu.se

${ }^{1}$ Department of Medical Sciences, Respiratory, Allergy and Sleep Research, Uppsala University, Uppsala, Sweden

${ }^{2}$ Population Health and Occupational Disease, National Heart and Lung

Institute, Imperial College, London, UK

Full list of author information is available at the end of the article
}

had had a least one episode of pneumonia during the 8 year observation period [3]. Pneumonia is also relatively common in asthma. In a recent observational study we found that the cumulative incidence of pneumonia was $16 \%$ during the seven year study period [4]. Other studies have found that subjects with asthma have a two to three times higher risk of pneumonia than subjects without asthma [5, 6]. Smoking, gastroesophageal reflux and heart disease have also been identified as risk factors for pneumonia $[5,6]$.

Treatment with inhaled corticosteroids is used in both asthma and COPD. In asthma, in particular there is good evidence that ICS reduces exacerbations, and so they are included in every major guideline [7]. In COPD, treatment with inhaled corticosteroids (ICS) increases the risk of pneumonia $[8,9]$. There is also an indication

(c) The Author(s). 2019 Open Access This article is distributed under the terms of the Creative Commons Attribution 4.0 International License (http://creativecommons.org/licenses/by/4.0/), which permits unrestricted use, distribution, and 
that this association may depend on the type of ICS prescribed, with several studies finding a higher risk for fluticasone propionate than budesonide [10-12]. In a systemic review Kew and Seniukovich found high quality evidence that fluticasone increased pneumonia events by 18 more per 1000 treated over 18 months, but there was less evidence for budesonide, with six more events per 1000 treated over nine months [13]. In asthma, however, the association between the use of ICS and pneumonia is less clear. O'Byrne and co-workers found no association between the use of budesonide and pneumonia, [14] whereas McKeever et al found a dose response relationship between the use of ICS and risk of pneumonia in asthmatics from primary care [15]. In that study an increased risk of pneumonia was found in patients treated with fluticasone propionate but not in those treated with budesonide. Recently Qian et al also found a dose related association between ICS use and pneumonia in asthma, but in that study this was found for both fluticasone propionate and budesonide [16].

The aim of this investigation was to examine risk factors for hospitalisations with pneumonia in the general population and to investigate risk factors for pneumonia in subjects with asthma with special emphasis on the use of ICS.

\section{Method}

\section{Population and methods}

The European Community Respiratory Health Survey (ECRHS) stage I took place in 1990-1994. In the study, males and females aged 20-44 years were randomly selected from the population register in participating centres [17]. A postal questionnaire was sent to $3000-4000$ subjects at each centre.

Respiratory Health In Northern Europe (RHINE) II is a follow-up study of participants from ECRHS stage 1 from seven Northern European centres [18]. RHINE II consisted of a postal questionnaire sent in 19992001. The questionnaire was sent out to all participants of ECRHS stage 1 (age 28-54 years). The present analysis is based on data from the three Swedish centres: Gothenburg, Uppsala and Umea, where $7340(79.3 \%)$ of the 9248 in the original sample participated. Written informed consent was obtained from each participant and the study was approved by the Regional Ethical Review Board in Uppsala, Sweden (1998/495).

Data on inpatient treatment for pneumonia (ICD 10Code J10-J18), including number of such hospitalisations was collected from the National Patient Register for the time period starting 1 January 2000 until 31st of December 2010 (Fig. 1). Data on date of death for the same time period was collected from the cause of death register.

Drug prescription data for hospital and primary care were collected from the Swedish Prescribed Drug Register from the time that the registry started 1st of July 2005 to the end of the study period: 31st of December 2010 (Fig. 1).

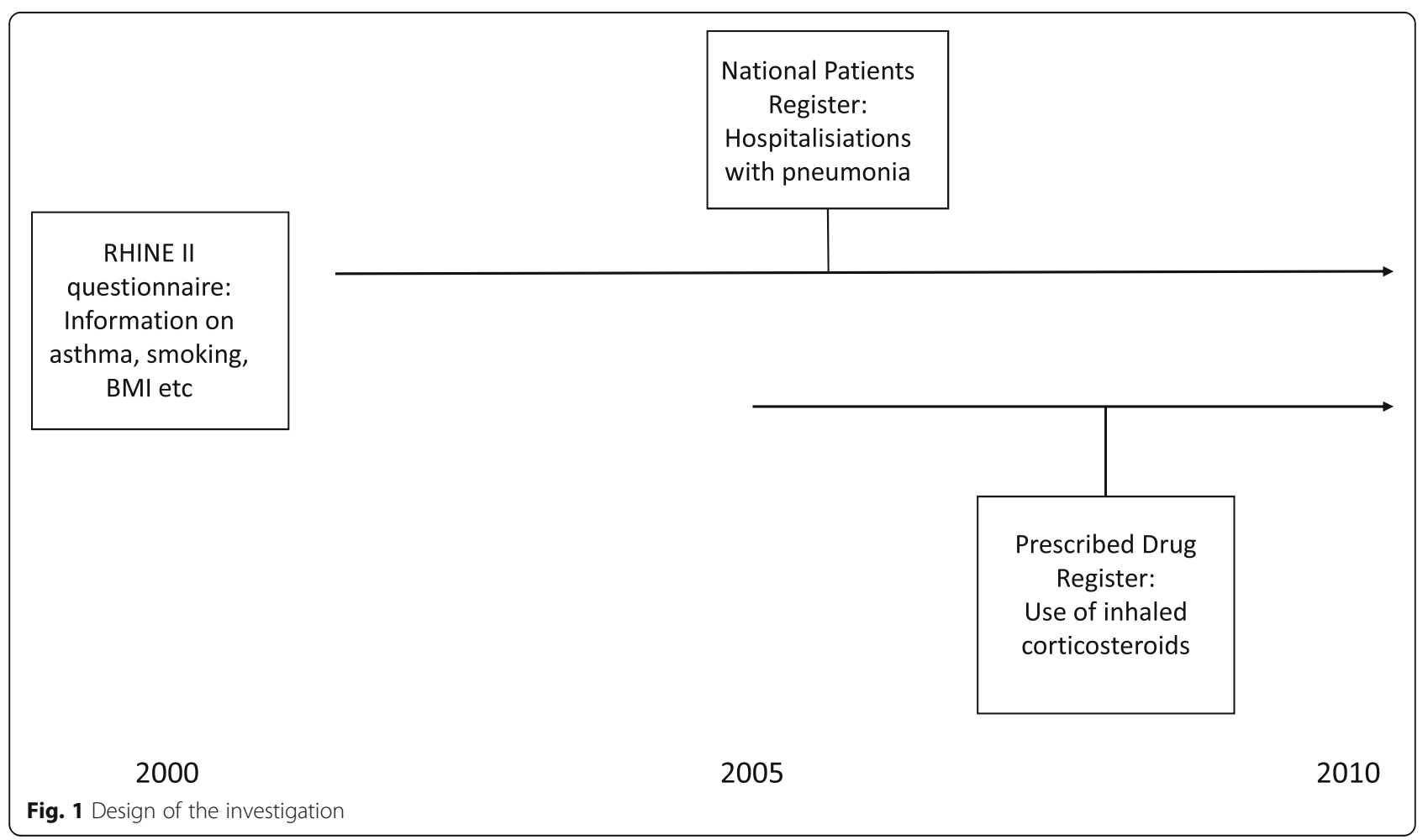




\section{Definition of analysed variables}

A hospitalisation with pneumonia was defined as a hospitalisation that included the ICD10 code J10-18 as one of the diagnostic codes.

Current asthma was defined as answering yes to the question:" Have you had an asthma attack during the last year?" and/or" Have you taken medication for asthma during the last year?" [19]. The number of asthma related symptoms (Yes/No) was assessed where the symptoms included were wheezing, wheezing in combination with breathlessness, wheezing when not having a cold, waking up with tightness in the chest and waking up with attacks of shortness of breath. The recall period for all symptoms was 12 months.

Nasal allergy was defined as answering yes to the question "Do you have any nasal allergies including hay fever?" [19] Nocturnal gastroesophageal reflux (nGER) was defined as reported heartburn or belching at least one night per week [20]. Habitual snoring was defined as loud and disturbing snoring at least 3 nights a week [21]. Hypertension was defined as answering yes to the question "Do you have hypertension?" and heart disease was defined in a similar way. Diabetes was defined as answering yes to the question: "Has a doctor told you that you have diabetes?"

Body mass index (BMI) was calculated from the selfreported height and weight and the participants grouped into four groups, <20, 20-25, > 25-30 and $>30 \mathrm{~kg} / \mathrm{m} 2$. Smoking history was captured through the questionnaire and the participants were categorised into neversmokers, ex-smokers and current smokers. Passive smoking was defined as being exposed to tobacco smoke at home every day and not being a current smoker [21].

Use of inhaled corticosteroids (ATC code R03BA and R03AK) was captured from the Prescribed Drug Registry. The number of years that the participants had collected at least one prescription was calculated where the maximum number of years was six. In a similar way information on the use of budesonide (ATC code R03BA02 and R03AK07) and fluticasone propionate (ATC code R03BA05, R03AK06 and R03AK11).

\section{Statistical analysis}

All analyses were performed using Stata version 14 (StataCorp, Texas, USA). Chi-2 test and unpaired t-test were used in bivariate analyses. Factors associated with the time to the first hospitalisation with pneumonia was analysed using Kaplan Meier and Cox proportional hazards models. All preselected variables were included in the model [22]. Participants were censored either at first hospitalisation with pneumonia, death or at 31st of December 2010. The proportional hazard assumption was tested for all the independent variables in the models and no violation was detected $(p>0.1)$, except for nasal allergy $(p=0.04)$.

The association between the yearly pneumonia event rate and use of ICS in participants with asthma was analysed with Poisson regression, with events as the dependent variable and number of years in the study as the offset variable. The independent variables were duration of the ICS treatment as a categorical variable, age, sex, BMI-groups, smoking history, centre and the number of asthma symptoms.

\section{Results}

Of the 7284 subjects included in the study 119 (1.6\%) had been hospitalized with pneumonia during the study period. Participants with pneumonia were more often women, older, more likely to have a BMI $<20$ or $>30 \mathrm{~kg} /$ $\mathrm{m} 2$, more often smokers and had a higher prevalence of asthma and heart disease than those that had not been hospitalised (Table 1).

Having asthma at baseline $(n=587)$ was significantly associated with a higher risk of being hospitalised with pneumonia independent of other risk factors (Fig. 2, Table 2). Apart from asthma, being hospitalised with pneumonia was independently associated with higher age, having a $\mathrm{BMI}<20$, a $\mathrm{BMI}>30$ and being a current smoker (Table 2).

\section{Participants with asthma.}

During the 6-year period there were 26 hospitalisations with pneumonia among the participants with asthma and 19 patients had at least one hospitalisation with pneumonia. Those with at least one hospitalisation with pneumonia were more often women, had more often a BMI $<20$ and were more likely to have used fluticasone propionate every year than those without a hospitalisation (Table 3). No significant difference was found between participants that had used fluticasone propionate and budesonide every year regarding age, sex, smoking history or number of symptoms (all $p$ values $>0.50$ ).

Having been hospitalised with pneumonia was independently associated with being female, having a BMI < 20 and having many symptoms. There was a trend between having used ICS in all of the six years during the observation period and being hospitalised with pneumonia (IRR (95\% CI) 2.48 (0.92-6.68)) (Table 4).

There was an independent association between having used fluticasone propionate (IRR (95\% CI) 7.92 (2.32-27.0)) during the whole observation period and hospitalisations with pneumonia, whereas no such association was found for budesonide (IRR (95\% CI) 1.23 (0.36-4.20)) (Fig. 3).

\section{Discussion}

The main finding of this investigation is that having asthma is associated with a three times higher risk of 
Table 1 Characteristics of participants that had not or had been hospitalised for pneumonia during the period $2000-2010$ (\% and mean \pm SD)

\begin{tabular}{llll}
\hline & No hospitalisation $(n=7168)$ & At least one hospitalisation $(n=119)$ & $p$-value \\
\hline Women & $3738(52.2)$ & $73(61.3)$ & $43.2 \pm 7.6$ \\
Age & $40.5 \pm 7.3$ & & $<0.001$ \\
BMI & & $18(15.4)$ \\
$<20$ & $387(5.4)$ & $41(35.0)$ \\
$20-25$ & $3681(51.8)$ & $41(35.0)$ \\
$25-30$ & $2450(34.5)$ & $17(14.5)$ \\
$>30$ & $582(8.2)$ & & \\
Smoking & & $48(40.7)$ \\
Never & $3620(51.8)$ & $20(17.0)$ \\
Ex & $1828(26.1)$ & $50(42.4)$ \\
Current & $1544(22.1)$ & $3(4.5)$ \\
Passive smoking ${ }^{a}$ & $178(3.3)$ & $26(21.8)$ \\
Asthma & $561(7.8)$ & $34(29.7)$ \\
Nasal allergy & $1728(24.5)$ & $11(9.3)$ \\
Hypertension & $459(6.5)$ & $5(4.2)$ \\
Heart disease & $73(1.0)$ & $3(2.6)$ \\
Diabetes & $131(1.8)$ & $23(20.4)$ & 0.001 \\
Habitual snoring & $1385(20.0)$ & $11(9.7)$ \\
Gastroesophageal reflux & $618(8.8)$ & 0.58 \\
\hline
\end{tabular}

Only calculated in never and ex-smokers

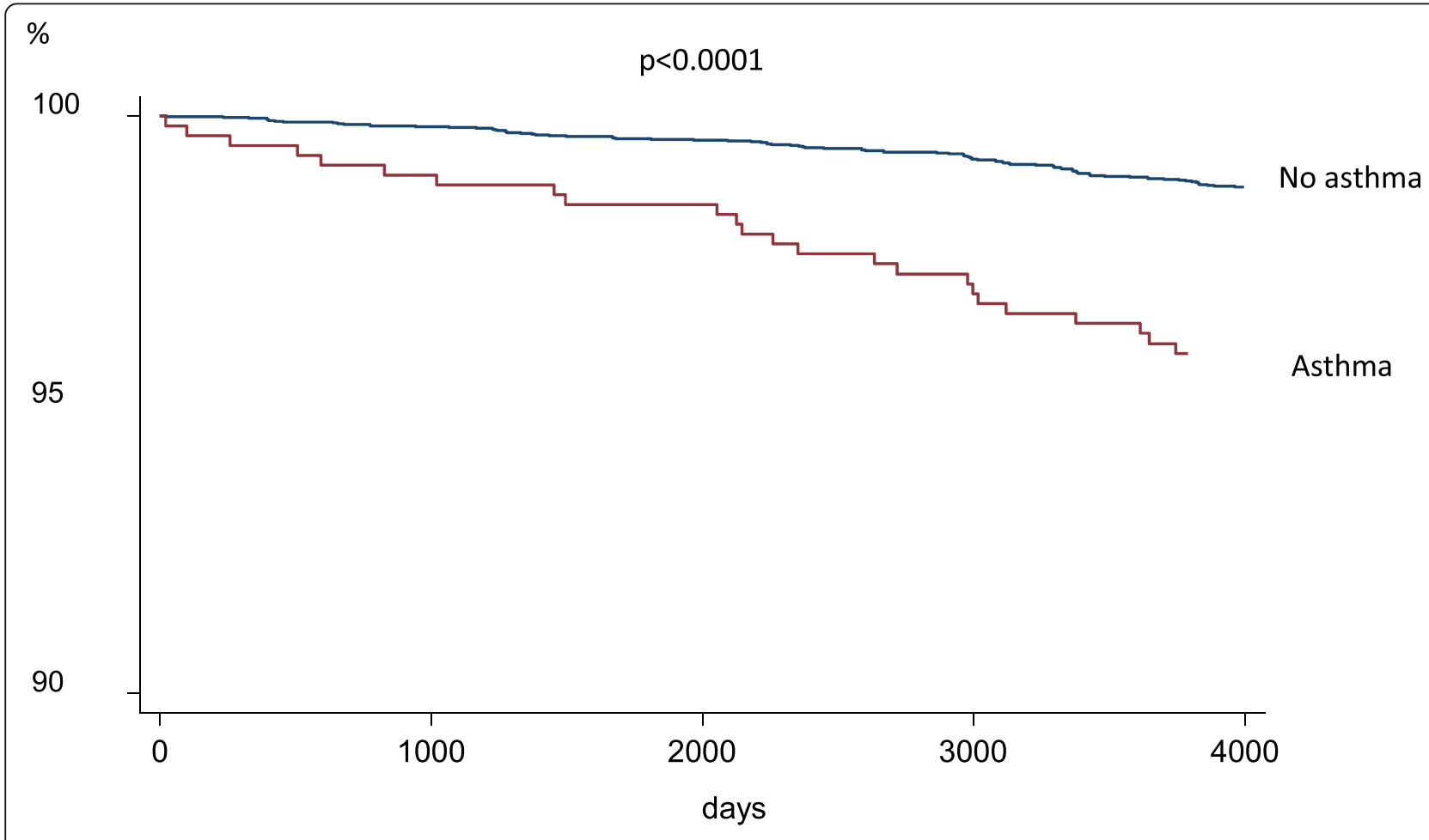

Fig. 2 Time to first hospitalisation with pneumonia in subjects with and without asthma 
Table 2 Association between factors measured at baseline and time to first hospitalisation with pneumonia (Hazard risk ratio (HRR) (95\% confidence interval))

\begin{tabular}{lll}
\hline & $\begin{array}{l}\text { Crude HRR } \\
(95 \% \mathrm{Cl})\end{array}$ & $\begin{array}{l}\text { Adjusted } \\
\operatorname{HRR}^{\mathrm{a}}(95 \% \mathrm{Cl})\end{array}$ \\
\hline $\begin{array}{l}\text { Women } \\
\text { Age per 10 years }\end{array}$ & $1.16(0.83-1.60)$ & $1.34(0.88-2.05)$ \\
BMI & $1.52(1.22-1.89)$ & $1.29(0.97-1.73)$ \\
$<20$ & $3.80(2.16-6.67)$ & $2.74(1.41-5.36)$ \\
$20-25$ & 1 & 1 \\
$25-30$ & $1.49(0.97-2.30)$ & $1.53(0.95-2.48)$ \\
$>30$ & $2.55(1.46-4.45)$ & $2.54(1.39-4.67)$ \\
Smoking & & \\
Never & 1 & 1 \\
Ex & $0.73(0.43-1.24)$ & $0.83(0.48-1.45)$ \\
Current & $1.95(1.30-2.95)$ & $1.93(1.22-3.06)$ \\
Passive smoking & & $1.27(0.31-5.30)$ \\
Asthma & $1.50(0.47-4.80)$ & $3.35(1.97-5.70)$ \\
Nasal allergy & $3.23(2.07-5.02)$ & $0.88(0.54-1.42)$ \\
Hypertension & $1.17(0.79-1.75)$ & $1.14(0.56-2.33)$ \\
Heart disease & $1.53(0.92-2.86)$ & $1.48(0.46-4.79)$ \\
Diabetes & $3.16(1.25-7.97)$ & $0.42(0.06-3.07)$ \\
Habitual snoring & $1.57(0.50-4.94)$ & $0.80(0.47-1.37)$ \\
Gastroesophageal reflux & $1.15(0.72-1.83)$ & $0.96(0.49-1.90)$ \\
\hline Adjusted for alt & $1.26(0.67-2.35)$ &
\end{tabular}

${ }^{a}$ Adjusted for all the variables in the table and centre

being hospitalised with pneumonia. Among subjects with asthma, the risk of being hospitalised with pneumonia was higher in those that were underweight and those with more symptoms. Among asthmatics, an increased risk of pneumonia was found in those treated with fluticasone propionate during the whole observation period whereas treatment with budesonide was not associated with being hospitalised with pneumonia.

The increased risk of pneumonia in subjects with asthma is in accordance with other studies [5, 6, 23]. There is also data suggesting that subjects with asthma may be more prone to get non-respiratory infections [23]. The reason for the increased risk of infections in asthma is not totally understood but an impaired immune response against bacterial infection might be part of the explanation [24]. Despite the increased risk, it should be emphasized that only $4 \%$ of participants with asthma were hospitalized with pneumonia during this 10 year period and that the risk is much lower than for instance patients with COPD [3].

Like many other studies, we found that being a current smoker is associated with an increased risk of pneumonia $[5,6,25,26]$. The reason for this is that smoking causes both morphological changes in the airway and inflammatory reactions including inhibition of innate and
Table 3 Characteristics of participants with asthma that had not or had been hospitalised for pneumonia during the period 2005-2010 ( $(\%)$ and mean \pm SD)

\begin{tabular}{|c|c|c|c|}
\hline & $\begin{array}{l}\text { No hospitalisation } \\
(n=567)\end{array}$ & $\begin{array}{l}\text { At least one } \\
\text { hospitalisation } \\
(n=19)\end{array}$ & P-value \\
\hline Women & $319(56)$ & $16(84)$ & 0.02 \\
\hline Age & $40 \pm 7$ & $40 \pm 0.75$ & \\
\hline BMI & & & 0.007 \\
\hline$<20$ & $26(5)$ & $4(21)$ & \\
\hline $20-25$ & $268(48)$ & $6(32)$ & \\
\hline $25-30$ & $196(35)$ & $5(26)$ & \\
\hline$>30$ & $70(12)$ & $4(21)$ & \\
\hline Smoking & & & 0.34 \\
\hline Never & $298(54)$ & $12(63)$ & \\
\hline Ex & $140(25)$ & $2(11)$ & \\
\hline Current & $117(21)$ & $5(26)$ & \\
\hline Number of Symptoms & $2.7 \pm 1.5$ & $3.4 \pm 1.3$ & 0.08 \\
\hline ICS (years) & & & 0.02 \\
\hline 0 & $238(42)$ & $6(32)$ & \\
\hline $1-5$ & $224(39)$ & $4(21)$ & \\
\hline 6 & $106(19)$ & $9(47)$ & \\
\hline Budesonide (years) & & & 0.52 \\
\hline 0 & 253 (44.) & $8(42)$ & \\
\hline $1-5$ & $245(43)$ & $7(37)$ & \\
\hline 6 & $70(12)$ & $4(21)$ & \\
\hline Fluticasone (years) & & & $<0.0001$ \\
\hline 0 & $345(61)$ & $7(37)$ & \\
\hline $1-5$ & $199(35)$ & $7(37)$ & \\
\hline 6 & $24(5)$ & $5(26)$ & \\
\hline
\end{tabular}

adaptive response to infections [27]. Passive smoking has also been associated with pneumonia in some studies [28]. We, however, found no association between passive smoking and pneumonia in non-smokers in the present study. The most likely explanation for this is the very low prevalence of passive smoking in this population [29].

In the present study, participants that were underweight and obese had an increased risk of being hospitalised with pneumonia. This is in accordance with some other studies $[5,26,30]$. The reason is probably that both being underweight and obesity may affect the immune system [30, 31]. Pneumonia has also been associated with other obesity related disorders such as obstructive sleep apnea [32] and nGER [33], but in the present study we found no association between habitual snoring or nGER and being hospitalised with pneumonia. Other studies have shown a higher risk of pneumonia in subjects with diabetes and cardiovascular disease [34]. This was not the case in the multiple variable 
Table 4 Independent risk factors for being hospitalised with pneumonia during July 2005 to December 2010 in participant with asthma (incidence risk ratio (IRR) (95\% confidence interval))

\begin{tabular}{ll}
\hline & $\operatorname{IRR}^{\mathrm{a}}(95 \% \mathrm{Cl})$ \\
\hline Age per 10 years & $5.66(1.26-25.3)$ \\
$\mathrm{BMI}$ & $1.13(0.60-2.14)$ \\
$<20$ & \\
$20-25$ & $7.80(2.31-26.3)$ \\
$25-30$ & 1 \\
$>30$ & $1.83(0.53-6.27)$ \\
Smoking & $2.27(0.65-7.90)$ \\
Never & \\
Ex & 1 \\
Current & $0.42(0.09-1.94)$ \\
Number of Symptoms & $1.73(0.69-4.35)$ \\
ICS (years) & $1.41(1.01-1.95)$ \\
0 & \\
$1-5$ & 1 \\
6 & $0.36(0.09-1.40)$ \\
\hline
\end{tabular}

${ }^{\mathrm{a}}$ Adjusted for all the variables in the table and centre analysis in our study and this is probably related to the relative young age of the population.

In the present study, we found that participants with asthma that had been using ICS every year had an almost three times higher risk of being hospitalised with pneumonia during the study period. Even though this association was of only of borderline significance the result is in accordance with what has been seen in other studies $[15,16,35]$. The risk was even higher in asthmatics that had been using fluticasone propionate each year while no increased risk was found in those using budesonide. This result is in accordance with what has been seen in COPD $[10,11,36]$. This result is also in accordance with that of O'Byrne et al were no increased risk was found between treatment of budesonide and pneumonia in asthma [14] and also to the results from McKeever and co-workers where the risk of pneumonia was higher with fluticasone propionate than budesonide [15]. The results are, however, not in accordance with those of Qian et al where the adjusted risk for pneumonia was higher for budesonide than fluticasone propionate [16]. No direct comparison of pneumonia risk between budesonide and fluticasone propionate was done in any of the two studies above. A difference between the present study and the studies by McKeever et al. an Qian et al. is that they studied all kinds of pneumonia event while the present study only studied

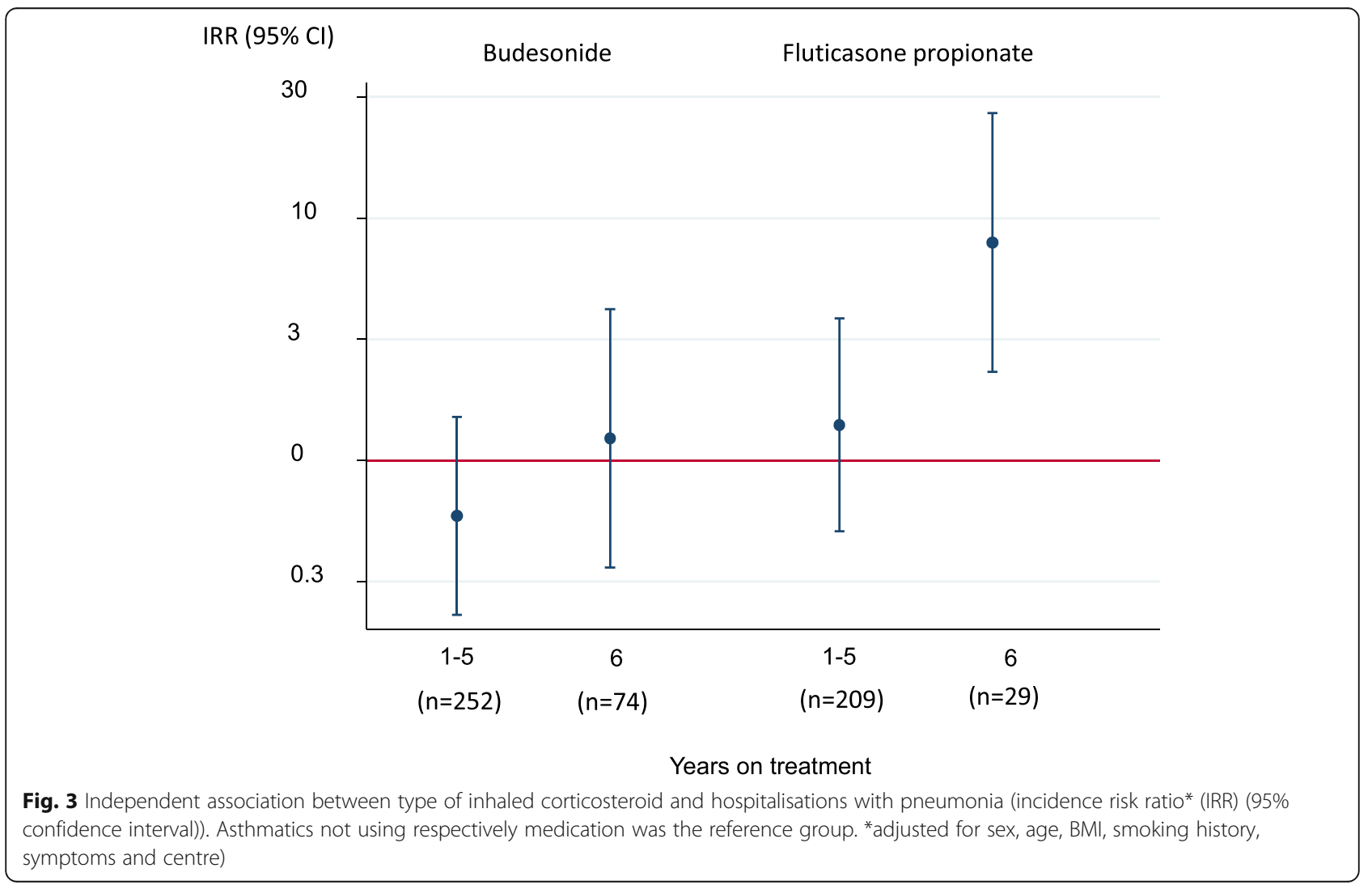


hospitalisations with pneumonia. If there is an intraclass difference between budesonide and fluticasone propionate in relation to the risk of pneumonia in asthma, this is probably explained by the difference in drug pharmacokinetics. Fluticasone propionate is less water-soluble and therefore more slowly dissolved from the airway luminal fluid than budesonide. This results in a more protracted immunosuppressive effect locally with fluticasone propionate than budesonide [37].

The strength of this investigation is that the data are from a longitudinal study with detailed information on a large number of potential risk factors at baseline. It is also a strength that we were able to combine that data with data from the national registries. We also believe that using hospitalisation with pneumonia is a strength as this makes the risk of misdiagnosis smaller as radiography is a standard procedure in investigation of pneumonia in inpatient care in Sweden [38]. The weakness is that the number of events was low which especially causes a problem when analysing the relation between ICS and pneumonia in asthma. We were therefore only able to identify factors with a high magnitude of risk. Another potential weakness is that all data, except the hospitalisations and medication data, was based on selfreported data which carries a risk of misclassification. Furthermore, apart from number of symptoms, which was only collected at one time point; we have not adjusted our analyses for asthma severity or control. Other residual confounders include treatment with oral corticosteroids and compliance to the collected ICS prescriptions.

\section{Conclusion}

We conclude that having asthma is associated with a three times higher risk of being hospitalised for pneumonia and that the risk of being hospitalised with pneumonia was increased in asthmatics that were underweight. This analysis also suggests an intraclass differences between ICS compounds when it comes to the risk of pneumonia, with an increased risk of pneumonia related to fluticasone propionate than for budesonide. The result concerning this intraclass difference was, however, based on a low number of events and should be confirmed in large clinical trials.

\footnotetext{
Abbreviations

BMI: Body mass index; COPD: Chronic obstructive pulmonary disease; ECRHS: European Community Respiratory Health Survey; HR: Hazard ratio; ICS: Inhaled corticosteroids; IRR: Incidence risk ratio; nGER: Nocturnal gastroesophageal reflux; RHINE: Respiratory Health In Northern Europe
}

\section{Acknowledgements}

We are grateful to Associate Professor Liisa Byberg at the Department of Surgical Sciences, Uppsala University with invaluable help when merging the RHINE dataset with national registry data.

\section{Authors' contribution}

The manuscript was drafted by EE and CJ. EE, CJ, JQ and DJ analysed the data. LS, AM, KF, MH, KT, EL and CJ collected the data. All authors' provided substantial contribution to the analysis and interpretation of data. All authors read and approved the final version of the manuscript.

\section{Funding}

The study was funded by the Swedish Heart and Lung Foundation, the Swedish Association Against Asthma and Allergy, the Swedish Association against Heart and Lung Disease, the Swedish Council for Working Life and Social Research and the Bror Hjerpstedt Foundation. The funders gave economical support to the study, but were not involved in in the design of the study, the collection of data, analysis, interpretation of data or in writing the manuscript. Open access funding provided by Uppsala University.

\section{Availability of data and materials}

The dataset is still subject to further analyses, but will continue to be held and managed by the Department of Medical Sciences, Uppsala University, Uppsala, Sweden. Relevant anonymised data are available on reasonable request from the authors. The questionnaire can be downloaded from the study website: www.rhine.nu

\section{Ethics approval and consent to participate}

Written informed consent was obtained from each participant and the study was approved by the Regional committees of medical research ethics in Uppsala: Reference mummers: 1998/495.

\section{Consent for publication}

Not applicable.

\section{Competing interests}

CJ has received payments for educational activities from AstraZeneca, Boehringer Ingelheim, Chiesi, Novartis and Teva, and has served on advisory boards arranged by AstraZeneca, Boehringer Ingelheim, Chiesi, GlaxoSmithKline, Novartis and Teva. EL has received payments for educational activities from AstraZeneca. None of the other authors have any competing interests to declare.

\section{Author details}

'Department of Medical Sciences, Respiratory, Allergy and Sleep Research, Uppsala University, Uppsala, Sweden. ${ }^{2}$ Population Health and Occupational Disease, National Heart and Lung Institute, Imperial College, London, UK. ${ }^{3}$ Department of Occupational and Environmental Medicine, University of Gothenburg, Gothenburg, Sweden. ${ }^{4}$ Department of Medical Sciences: Clinical Physiology, Uppsala University, Uppsala, Sweden. ${ }^{5}$ Department of Surgical and Perioperative Sciences, Umeå University, Umeå, Sweden.

Received: 30 March 2019 Accepted: 11 December 2019

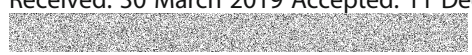

\section{References}

1. Jain $\mathrm{S}$, Self WH, Wunderink RG, Fakhran S, Balk R, Bramley AM, Reed C, Grijalva CG, Anderson EJ, Courtney DM, et al. Community-acquired pneumonia requiring hospitalization among U.S. adults. N Engl J Med. 2015; 373:415-27.

2. Bjarnason A, Westin J, Lindh M, Andersson LM, Kristinsson KG, Love A, Baldursson O, Gottfredsson M. Incidence, Etiology, and Outcomes of Community-Acquired Pneumonia: A Population-Based Study. Open Forum Infect Dis. 2018;5(2):ofy010

3. Stallberg B, Janson C, Johansson G, Larsson K, Stratelis G, Telg G, Lisspers $\mathrm{KH}$. Management, morbidity and mortality of COPD during an 11-year period: an observational retrospective epidemiological register study in Sweden (PATHOS). Prim Care Respir J. 2014;23:38-45.

4. Lisspers K, Janson C, Larsson K, Johansson G, Telg G, Thuresson M, Stallberg B. Comorbidity, disease burden and mortality across age groups in a Swedish primary care asthma population: an epidemiological register study (PACEHR). Respir Med. 2018;136:15-20.

5. Almirall J, Bolibar I, Serra-Prat M, Roig J, Hospital I, Carandell E, Agusti M, Ayuso P, Estela A, Torres A. New evidence of risk factors for community-acquired pneumonia: a population-based study. Eur Respir J. 2008:31:1274-84. 
6. Teepe J, Grigoryan L, Verheij TJ. Determinants of community-acquired pneumonia in children and young adults in primary care. Eur Respir J. 2010; 35:1113-7.

7. "Global strategy for asthma management and prevention: GINA executive summary." E.D. Bateman, S.S. Hurd, P.J. Barnes, J. Bousquet, J.M. Drazen, J.M. FitzGerald, P. Gibson, K. Ohta, P. O'Byrne, S.E. Pedersen, E. Pizzichini, S.D. Sullivan, S.E. Wenzel and H.J. Zar. Eur Respir J 2008; 31: 143-178. Eur Respir J. 2018;51(2):pii: 0751387

8. Ernst P, Gonzalez AV, Brassard P, Suissa S. Inhaled corticosteroid use in chronic obstructive pulmonary disease and the risk of hospitalization for pneumonia. Am J Respir Crit Care Med. 2007;176:162-6.

9. Crim C, Calverley PM, Anderson JA, Celli B, Ferguson GT, Jenkins C, Jones PW, Willits LR, Yates JC, Vestbo J. Pneumonia risk in COPD patients receiving inhaled corticosteroids alone or in combination: TORCH study results. Eur Respir J. 2009:34:641-7.

10. Janson C, Larsson K, Lisspers KH, Stallberg B, Stratelis G, Goike H, Jorgensen $\mathrm{L}$, Johansson $\mathrm{G}$. Pneumonia and pneumonia related mortality in patients with COPD treated with fixed combinations of inhaled corticosteroid and long acting beta2 agonist: observational matched cohort study (PATHOS). BMJ. 2013;346:f3306

11. Suissa S, Patenaude V, Lapi F, Ernst P. Inhaled corticosteroids in COPD and the risk of serious pneumonia. Thorax. 2013;68:1029-36.

12. Yang HH, Lai CC, Wang YH, Yang WC, Wang CY, Wang HC, Chen L, Yu CJ. Severe exacerbation and pneumonia in COPD patients treated with fixed combinations of inhaled corticosteroid and long-acting beta2 agonist. Int J Chron Obstruct Pulmon Dis. 2017;12:2477-85.

13. Kew KM, Seniukovich A. Inhaled steroids and risk of pneumonia for chronic obstructive pulmonary disease. Cochrane Database Syst Rev. 2014 CD010115.

14. O'Byrne PM, Pedersen S, Carlsson LG, Radner F, Thoren A, Peterson S, Ernst $P$, Suissa S. Risks of pneumonia in patients with asthma taking inhaled corticosteroids. Am J Respir Crit Care Med. 2010;183:589-95.

15. McKeever T, Harrison TW, Hubbard R, Shaw D. Inhaled corticosteroids and the risk of pneumonia in people with asthma: a case-control study. Chest. 2013;144:1788-94

16. Qian CJ, Coulombe J, Suissa S, Ernst P. Pneumonia risk in asthma patients using inhaled corticosteroids: a quasi-cohort study. Br J Clin Pharmacol. 2017:83:2077-86

17. Burney PG, Luczynska C, Chinn S, Jarvis D. The European Community respiratory health survey. Eur Respir J. 1994;7:954-60.

18. Gunnbjornsdottir MI, Omenaas E, Gislason T, Norrman E, Olin AC, Jogi R, Jensen EJ, Lindberg E, Bjornsson E, Franklin K, et al. Obesity and nocturnal gastro-oesophageal reflux are related to onset of asthma and respiratory symptoms. Eur Respir J. 2004;24:116-21.

19. Variations in the prevalence of respiratory symptoms, self-reported asthma attacks, and use of asthma medication in the European Community Respiratory Health Survey (ECRHS). Eur Respir J. 1996:9:687-95.

20. Emilsson OI, Janson C, Benediktsdottir B, Juliusson S, Gislason T. Nocturnal gastroesophageal reflux, lung function and symptoms of obstructive sleep apnea: results from an epidemiological survey. Respir Med. 2012;106:459-66.

21. Franklin KA, Gislason $T$, Omenaas $E$, Jogi $R$, Jensen $E J$, Lindberg $E$, Gunnbjornsdottir M, Nystrom L, Laerum BN, Bjornsson E, et al. The influence of active and passive smoking on habitual snoring. Am J Respir Crit Care Med. 2004;170:799-803.

22. Heinze G, Dunkler D. Five myths about variable selection. Transpl Int. 2017 30:6-10.

23. Helby J, Nordestgaard BG, Benfield T, Bojesen SE. Asthma, other atopic conditions and risk of infections in 105519 general population never and ever smokers. J Intern Med. 2017;282:254-67.

24. Juhn YJ. Risks for infection in patients with asthma (or other atopic conditions): is asthma more than a chronic airway disease? J Allergy Clin Immunol. 2014;134:247-57 quiz 258-249.

25. Nuorti JP, Butler JC, Farley MM, Harrison LH, McGeer A, Kolczak MS, Breiman RF. Cigarette smoking and invasive pneumococcal disease. Active bacterial Core surveillance team. N Engl J Med. 2000;342:681-9.

26. Baik I, Curhan GC, Rimm EB, Bendich A, Willett WC, Fawzi WW. A prospective study of age and lifestyle factors in relation to communityacquired pneumonia in US men and women. Arch Intern Med. 2000;160: 3082-8

27. Almirall J, Blanquer J, Bello S. Community-acquired pneumonia among smokers. Arch Bronconeumol. 2014;50:250-4.
28. Almirall J, Serra-Prat M, Bolibar I, Palomera E, Roig J, Hospital I, Carandell E, Agusti $\mathrm{M}$, Ayuso P, Estela A, et al. Passive smoking at home is a risk factor for community-acquired pneumonia in older adults: a population-based case-control study. BMJ Open. 2014:4:e005133.

29. Janson C, Kunzli N, de Marco R, Chinn S, Jarvis D, Svanes C, Heinrich J, Jogi R, Gislason T, Sunyer J, et al. Changes in active and passive smoking in the European Community respiratory health survey. Eur Respir J. 2006;27:517-24.

30. Phung DT, Wang Z, Rutherford S, Huang C, Chu C. Body mass index and risk of pneumonia: a systematic review and meta-analysis. Obes Rev. 2013; 14:839-57.

31. Almirall J, Bolibar I, Serra-Prat M, Roig J, Hospital I, Carandell E, Agusti M, Ayuso P, Estela A, Torres A. Community-acquired pneumonia in Catalan countries study $\mathrm{G}$ : new evidence of risk factors for community-acquired pneumonia: a population-based study. Eur Respir J. 2008;31:1274-84.

32. Chiner E, Llombart M, Valls J, Pastor E, Sancho-Chust JN, Andreu AL, Sanchez-de-la-Torre M, Barbe F. Association between obstructive sleep apnea and community-acquired pneumonia. PLoS One. 2016;11:e0152749.

33. Gaude GS. Pulmonary manifestations of gastroesophageal reflux disease. Ann Thorac Med. 2009;4:115-23.

34. Rivero-Calle I, Pardo-Seco J, Aldaz P, Vargas DA, Mascaros E, Redondo E, Diaz-Maroto JL, Linares-Rufo M, Fierro-Alacio MJ, Gil A, et al. Incidence and risk factor prevalence of community-acquired pneumonia in adults in primary care in Spain (NEUMO-ES-RISK project). BMC Infect Dis. 2016;16:645.

35. Zhang L, Prietsch SO, Mendes AP, Von Groll A, Rocha GP, Carrion L, Da Silva $P E$. Inhaled corticosteroids increase the risk of oropharyngeal colonization by Streptococcus pneumoniae in children with asthma. Respirology. 2013; 18:272-7.

36. Fox RA. Treatment recommendations for respiratory tract infections associated with aging. Drugs Aging. 1993;3:40-8.

37. Janson C, Stratelis G, Miller-Larsson A, Harrison TW, Larsson K. Scientific rationale for the possible inhaled corticosteroid intraclass difference in the risk of pneumonia in COPD. Int J Chron Obstruct Pulmon Dis. 2017;12:3055-64.

38. Spindler C, Stralin K, Eriksson L, Hjerdt-Goscinski G, Holmberg H, Lidman C, Nilsson A, Ortqvist A, Hedlund J. Community acquired pneumonia working Group of the Swedish Society of infectious D: Swedish guidelines on the management of community-acquired pneumonia in immunocompetent adults--Swedish Society of Infectious Diseases 2012. Scand J Infect Dis. 2012 44:885-902

\section{Publisher's Note}

Springer Nature remains neutral with regard to jurisdictional claims in published maps and institutional affiliations.

Ready to submit your research? Choose BMC and benefit from:

- fast, convenient online submission

- thorough peer review by experienced researchers in your field

- rapid publication on acceptance

- support for research data, including large and complex data types

- gold Open Access which fosters wider collaboration and increased citations

- maximum visibility for your research: over $100 \mathrm{M}$ website views per year

At $\mathrm{BMC}$, research is always in progress.

Learn more biomedcentral.com/submissions 